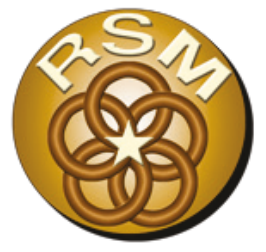

\title{
Physical Monitoring Methods for the Nearshore Placement of Dredged Sediment
}

\author{
by Zachary J. Tyler, Brian C. McFall, Katherine E. Brutsché, \\ Erin C. Maloney, and David F. Bucaro
}

PURPOSE: This Regional Sediment Management Technical Note (RSM-TN) provides an introduction to equipment and methods for monitoring the nearshore placement of dredged sediment. Topical information regarding instrumentation, physical monitoring techniques, and field operations planning is included and closes with an example monitoring plan from Ogden Dunes, IN. This overview is intended for U.S Army Corps of Engineers (USACE) District Project Managers, Planners, and Engineers tasked with developing a plan to monitor the evolution of a nearshore placement and its impact to adjacent beaches.

BACKGROUND: The placement of dredged sediment in the nearshore zone is a common method used in regional sediment management (RSM) due to its potential benefits including the addition of material to the littoral system, enhancement of the beach profile, and reduction of wave energy on the beach. The term nearshore placement refers to the practice of placing material subaqueously in the nearshore zone regardless of shape of the designed feature. Nearshore placements are often referred to as nearshore berms when constructed to be a specific shape, typically a bar or mound. The USACE generally does not require physical monitoring of nearshore placements, but local, state, or regulatory entities may require placement areas be monitored in order to quantify benefits or any potential negative impacts (Beck et al. 2012). These effects may include finegrained sedimentation of beaches as well as sediment transport into navigational channels or environmentally sensitive areas. The quantification of benefits, effects, and behavior of nearshore placement projects is important in optimizing their use as an RSM strategy.

MEASUREMENT INSTRUMENTATION AND TECHNIQUES: The important measurement parameters in nearshore placement monitoring fall into three categories. The first category includes spatiotemporal geomorphic parameters such as location, depth, dimensions, and placement volume and their changes over time. These parameters are often measured using bathymetric and topographic surveying or remote sensing approaches. The second category includes geophysical sediment and fluid parameters such as grain size, porosity, relative density of the native and placed sediments, turbidity, and sediment transport rate. These parameters are quantified using sediment and water sampling in conjunction with in situ measurements. The third category is focused on measuring hydrodynamic parameters such as wave height, wave period, wave direction (for offshore and nearshore waves), water level (including tide, wind, and wave-driven components), flow velocity, and flow direction. Hydrodynamic parameters are generally measured using in situ instruments mounted on the seafloor or in the water column and more recently can also be measured using remotely sensed data. 
In nearshore placement monitoring, the required parameters and environmental considerations specific to the study area will determine which instruments and techniques can be employed. The majority of this section highlights instrument capabilities, limitations, and recommendations with regard to nearshore placement monitoring. A brief discussion of new, remotely sensed video and radar imaging techniques completes this section.

Bathymetric and Topographic Surveying. Bathymetric and topographic surveying is often a principal component of nearshore placement monitoring. The observation of the anthropogenically and naturally induced changes in nearshore morphology allows for quantification of benefits such as the seaward enhancement of the beach profile. Alternatively, surveying may reveal or address potential concerns such as the spreading of placement material into a navigation channel or other sensitive areas. For those that are developing and executing a nearshore placement monitoring plan using surveying, there are two main considerations to be addressed. First, the location of the placement with respect to features such as beaches or navigation channels may necessitate denser survey coverage within and in the vicinity of those features. Second, the size and dimensions of the placement vs. survey resolution requirements must be considered; in general, the larger the placement, the larger the survey data requirements will be to achieve an adequate resolution for analysis. The remainder of this section discusses survey design, methods, and equipment.

Bathymetric and topographic survey design depends largely on the type of information desired to be gathered as well as the considerations discussed above. High-interest areas, such as navigation channels or the inner-surf zone where beach recovery occurs, may need to be surveyed more densely or frequently. If possible, a control area should be established in the vicinity of the placement area. A control area is useful to analyze the physical shoreline response to the placement by comparing the response to an area without a placement. The control area should exhibit similar historical trends and environmental conditions as the placement area but be located far enough away to not be influenced by the placement. Optimally, the control area would be surveyed at the same spatial and temporal resolution as the placement area, but it is not necessary. Bathymetric and topographic surveying may be accomplished using ground-based real-time kinematic global positioning systems (RTK-GPS), rod and prism surveys, vessel-based acoustic surveying, ground-based light detection and ranging systems (lidar), or airborne lidar systems. Each technique is briefly described below, and then the resolution, cost, and accuracy of the approaches are compared and contrasted in a summary table at the end of this section.

Ground-based RTK-GPS or vessel-based hydrographic surveys are generally conducted along shore-normal transects that extend across the sub-aerial and sub-aqueous portion of the nearshore profile to the local depth of closure for active berms. For stable berms, transects may be confined in the cross-shore to a smaller region. For more information about active vs. stable nearshore placements, see Hands and Allison (1991); for more information about the concept of depth of closure, see Kraus et al. (1998). Cross-shore transects are spaced 30 to 150 meters (m) apart to capture a minimum of 10 to 20 transects over a nearshore placement area (Beck et al. 2012). Transects should extend at least $600 \mathrm{~m}$ downdrift and $300 \mathrm{~m}$ updrift of the placement. A few shore-parallel transects may be added for additional detail over the feature. For beach and very shallow water measurements $(h<1 \mathrm{~m})$, RTK-GPS and electronic total stations (ETS) with a rod and prism are preferred. The combination of RTK-GPS and ETS allows for efficient, repeatable, and high-accuracy (2-4 centimeters [cm] horizontal and vertical accuracy) measurements of a coastal area. A morphological approach to survey shot spacing is preferred over regular interval 
spacing. This approach will allow for better quantification of morphological change; for more information on coastal morphological features, see Masselink and Kroon (2009). For deeper water bathymetric measurements, hydrographic single-beam and multi-beam sonar devices are used. Geomorphologic ground- and vessel-based surveying are common and effective measurement techniques of nearshore placements (Brutsché et al. 2014; Brutsché et al. 2015; Wang et al. 2013). Additional guidance for geomorphologic surveying including theory of operation, planning considerations, and data processing is detailed in the USACE Engineer Manual Hydrographic Surveying (USACE 2013).

Lidar systems may be used to measure the three-dimensional bathymetric surface of a nearshore placement and topographic accretion caused by the evolution of the placement. Lidar systems can be mounted on airborne platforms, such as fixed or rotary-wing aircraft, and terrestrial platforms, such as utility vehicles or a tripod. Airborne systems often have the ability to measure both topography and bathymetry while terrestrial systems can measure only upland topography. Airborne systems provide approximately 1 point per square meter $\left(\mathrm{m}^{2}\right)$ with a horizontal accuracy of $1 \mathrm{~m}$ and a vertical accuracy of $0.2 \mathrm{~m}$ and can survey hundreds of kilometers of coastline in a day. Terrestrial systems mounted on a mobile platform provide hundreds of points $/ \mathrm{m}^{2}$ with a horizontal accuracy of $0.08 \mathrm{~m}$ and a vertical accuracy of $0.1 \mathrm{~m}$ and can survey tens of kilometers of coastline in a day (Spore and Brodie 2017). Stationary terrestrial systems collect similar resolution to mobile systems but with a higher accuracy of 0.02 to $0.04 \mathrm{~m}$ over smaller regions on the order of hundreds of meters. Recently, topographic lidar systems have also been mounted to unmanned aerial systems (UAS); however, UAS cannot presently carry bathymetric lidar systems due to weight and electrical power limitations.

The USACE Joint Airborne Lidar Bathymetry Technical Center of Expertise (JALBTCX) operates the Coastal Zone Mapping and Imaging Lidar (CZMIL) (Tuell et al. 2010). CZMIL operates on an airborne platform and is a combination lidar, hyperspectral imager, and red-green-blue camera. Through the National Coastal Mapping Program, JALBTCX has imaged most of the U.S coastline at least once and in some locations on a recurring basis, so it may provide background information or be used as a pre-construction baseline. If a flight is coincidently made after construction, it could be used instead of a planned bathymetric or topographic survey. Airborne lidar systems may struggle to provide complete bathymetric surfaces in turbid or actively breaking surf zones, but when conditions are suitable (e.g., optically clear, low-wave environments), can provide excellent three-dimensional data of the seafloor that can be used to evaluate nearshore morphology change (Beck et al. 2012). JALBTCX may be commissioned by district planners and engineers to perform lidar scans of nearshore placement projects and thereby may be an alternative to similar data collection options such as bathymetric and topographic surveying. Additional information on airborne lidar can be found on the JALBTCX website (https://shoals.sam.usace.army.mil/).

Terrestrial lidar refers to ground-based lidar scanners that are deployed on a stationary platform such as a tripod or mobile platform such as an all-terrain vehicle or vessel. To produce georectified data, the lidar scanner must be integrated with a global positioning system (GPS) or utilize ground rectification points at known coordinates. In nearshore placement monitoring, terrestrial lidar may be useful in scanning the subaerial beach adjacent to placed material. A time series of high-accuracy lidar scans of the subaerial beach would be useful in quantifying potential material transport from the placement to the beach. Disadvantages of terrestrial lidar include large data sets that often require editing to remove artifacts such as people, beach umbrellas, vehicles, sand 
fences, buildings, vegetation, etc. Additionally, sub-aqueous areas cannot be lidar scanned due to the frequency of light used (generally 1,550 nanometers [nm]), which attenuates rapidly in water.

The combination of a UAS platform with photogrammetry may be a cost-effective method to provide data of similar resolution to terrestrial lidar; however, the accuracy of these approaches is still being evaluated. Structure-from-Motion (SfM) photogrammetry can generate topographic products of the subaerial beach such as digital surface models and orthophotographs using overlapping digital images with visible control targets from different viewpoints (Westoby et al. 2012). When combined with detailed trajectory information or ground control points, accuracies may be on the order of $0.1 \mathrm{~m}$ in the vertical (Brunier et al. 2016). The SfM method can be applied to ground-based images or aerial images from UAS or other types of aircraft. This method is a new technique that has been used in many different types of geomorphological analysis, including the geomorphic evolution of beaches, and when used properly, may provide a cost-effective method of beach topographic surveying.

Table 1 summarizes the various tradeoffs between accuracy, resolution, time, and cost of the aforementioned bathymetric and topographic surveying techniques.

\begin{tabular}{|c|c|c|c|c|c|}
\hline Survey Technique & $\begin{array}{c}\text { Vertical } \\
\text { Accuracy }(m)\end{array}$ & Resolution & Field Time & $\begin{array}{c}\text { Processing } \\
\text { Time }\end{array}$ & Cost \\
\hline Ground-based GPS & $0.02-0.04$ & Low-Medium & High & Low & Medium \\
\hline $\begin{array}{l}\text { Vessel-based } \\
\text { bathymetry }\end{array}$ & $0.06-0.09$ & High & Medium & Medium & Medium \\
\hline Aerial lidar & 0.2 & Medium-High & Low & High & High \\
\hline Terrestrial lidar & 0.1 & High & Medium & High & $\begin{array}{l}\text { Medium- } \\
\text { Low }\end{array}$ \\
\hline Photogrammetry & 0.1 & Medium-High & Low-Medium & High & $\begin{array}{l}\text { Low- } \\
\text { Medium }\end{array}$ \\
\hline
\end{tabular}

Altimetry. An altimeter is an instrument that uses high-frequency sonic pulses to continuously measure the distance between the sensor and the seafloor at one location at high temporal resolution (Moulton et al. 2014). In nearshore placement monitoring, this type of device may be useful in determining vertical deflation. Laboratory analysis of the accuracy of sub-aqueous altimeters (also referred to as an ultra-sonic depth probe) performed by Friedrich et al. (2005) and the U.S. Army Engineer Research and Development Center (ERDC) indicate that these devices can achieve an accuracy of \pm 1.0 millimeter $(\mathrm{mm})$. Field analysis of the accuracy of these devices indicates an accuracy of $\pm 2-3 \mathrm{~cm}$ by Gallagher et al. (1996) and $\pm 8 \mathrm{~cm}$ as determined by Jestin et al. (1998). Altimeters use similar technology to vessel-based hydrographic surveying, but it is typically deployed as a semi-permanent, in situ sensor on a fixed pipe or platform in the water column. The immovability of the platform is an important factor in achieving the highest accuracies possible in a field environment. Underwater altimeters are designed to operate at a variety of depths and conditions, but bathymetric measurements may become discontinuous in breaking wave conditions, and there is potential for the instrument to be buried in settings with a dynamic bed. To achieve the highest accuracy possible, an external temperature gauge should be located halfway between the altimeter and the bed for speed of sound corrections. Salinity may 
also need to be considered as the speed of sound is slower in fresh water; a constant correction will suffice in environments where salinity does not change appreciably. Positioning the altimeter as closely as possible to the bed will aid in achieving high-accuracy measurements. Also, an altimeter may be co-located with other instruments to quantify the distance above or below the reference surface of the other instrument(s) (Elgar et al. 2001).

Sediment Sampling. Often, nearshore placement consists of sediment that is not typically compatible with beach sediment (i.e., may contain excessive fines). Periodic sediment sampling of a nearshore placement area can be necessary in these cases to document the sedimentological evolution of the placement and surrounding areas. When nearshore placements are constructed with sediments that are relatively different than native sediments, sediment sampling can help determine the migration of the berm (Anders and Clausner 1989). Depending on the goal of the monitoring program, it may be warranted to sample the borrow area, the placement area, and the control area. Sampling of the borrow area is useful to quantify the geotechnical character of the material prior to dredging. Sampling of the placement proper is useful when performed prior to, immediately after, and periodically after placement to quantify the geotechnical evolution of the placement. Sampling of the area surrounding the placement such as beaches, navigation channels, or other sensitive areas is useful when performed prior to, immediately after, and periodically after placement to quantify any changes to the natural spatial variability of seafloor and beach sediments after construction. Sampling the surrounding area is particularly useful if the bathymetry of an area appears unchanged but the material characteristics become more similar to that of the placement than the native material. This may occur when native material is supplanted by with placement material. Sampling of the control site will provide information on seasonal sedimentary changes that will aid in determining the changes induced by the placement on adjacent beaches. The use of sediment sampling is common in nearshore placement monitoring, but it is most effective when the placed sediment is significantly different than the native nearshore and beach sediment.

The method used to collect sediment depends largely on site conditions and monitoring objectives and is usually carried out by coring, grab sampling, direct sampling, or some combination thereof. Ideally, coring would be accomplished at the borrow area before dredging and at the placement area after construction. Coring has the benefit of obtaining large and deep sediment samples, which may show different sediment characteristics in the form of layered beds. The coring method has little chance of certain sediment sizes such as fine-grained material being lost or excluded during the sampling process. A limitation of coring is that it is often costly, time consuming, and that it requires specific equipment and trained personnel. Grab sampling is accomplished by lowering from a vessel a specialized instrument such as a Van Veen, Ponar, or Box sampler that grabs a sediment sample from the bed surface. The benefit of this method is that a large number of samples can be obtained over a short period of time. Limitations of the grab sampling method are that finegrained sediment that is grabbed has the potential to be lost between the time the sample is grabbed and finally stored, and it does not preserve stratigraphy. Direct sampling is accomplished by collecting and storing a surface sediment sample all within the same container. This method is useful in sampling the beach, intertidal, and swash zones. An example of direct sampling would be the use of a jar or similar container to insert into the sediment surface, remove the sample, then seal the sample with a lid. The main benefit of this method is that there is little chance that material will be lost or excluded from the sample. The direct sampling method cannot be easily accomplished in deep water, nor does it preserve stratigraphy. Tetra Tech EM Inc. (2003) documented a thorough 
review and discussion of sediment sampling devices, and Poppe et al. (2000) detail sediment analysis methods.

The location of sediment samples also depends largely on site conditions and monitoring objectives. Ideally, one sample for every 500 linear feet of placement with samples distributed amongst the crest and flanks of the placement should be taken (Anders 1989). Samples taken from the placement site would ideally be obtained during bathymetric surveys and their locations recorded, but it would also be sufficient to measure the sample coordinates and elevation if collected while not conducting a bathymetric survey. If sampling of adjacent and control beaches is to be conducted, the samples should be taken in a cross-shore manner with their locations recorded, preferably during a beach profile survey. Geomorphologic features to be sampled include the dune, backbeach, active beach berm, escarpment, bar trough, bar crest, landward slope of the placement, placement crest, and seaward slope of placement (Beck et al. 2012). Sediment samples may need to be focused on specific transects of interest depending upon time and funding constraints. Transects of interest may include the center of the placement, at the along-shore terminuses, and updrift and downdrift of the placement area. Site conditions, monitoring objectives, as well as sampling methods available largely determine the location where sediment is collected.

Water Quality Measurements. If the material to be used for a nearshore placement has a significant amount of fine-grained material, it may be beneficial or required to monitor turbidity or the total suspended solids concentration. These may be measured with properly calibrated acoustic or optical devices. Acoustic devices include dedicated acoustic backscatter sensors as well as acoustic Doppler current profilers (ADCP) and acoustic Doppler velocimeters (ADV). Optical devices include optical backscatter sensors and laser in situ scattering and transmissometers (Johnson and Work 2005). Care should be taken in selecting optical turbidity measurement devices and in performing data analysis since different makes/models of devices may not be comparable to each other. There are two units of measurement for turbidity: nephelometric turbidity units (NTU), which are measured using white light, and formazin nephelometric units, which are measured using infrared light. These units are not directly comparable (Anderson 2005). In nearshore monitoring, these types of devices may be useful in quantifying water quality before, during, and after placement. Monitoring prior to placement will provide information on the natural variability of water quality. Monitoring during placement will provide information on water quality when total suspended solids concentrations are likely elevated. Monitoring after placement will provide information on longer-term water quality as the placement evolves. The location where these devices should be placed will largely be determined by site conditions. Ideally, they would be placed downdrift and updrift of a placement. The control area and any ecologically sensitive areas should have a turbidity sensor placed nearby.

In Situ Wave and Current Measurement. Waves and currents are the driving forces that result in the movement of nearshore placement sediment. Directional wave and current measurements are useful when collected both seaward and landward of the placement to provide data on wave dissipation, wave direction modification, and changes in nearshore waves and currents as a result of the nearshore placement. These data are most often collected through the temporary, rigid, installation of instruments on the seafloor. The control area is most beneficial when gauged in a similar fashion with instruments at similar depths and distances from the shore. 
A wide variety of instruments are available for wave and current measurements: wave and current profilers (including ADCP, acoustic wave and current profilers and Aquadopp Profilers), ADVs, and pressure sensors. Pressure sensors provide non-directional wave information in shallow water. Wave and current profiling gauges and ADVs utilize the acoustic Doppler shift from sediment in the sample volume to determine the relative movement of the fluid. When used in combination with a pressure gauge, horizontal and axial velocity measurement techniques can be used to estimate directional wave spectra and currents. Wave and current profilers can measure the direction of current over a range of depths to produce a current profile whereas ADVs measure velocity and three-dimensional directions of currents at a minuscule volume very near the sensor (Lohrmann et al. 1994; Russello et al. 2006).

In nearshore placement monitoring, ADCPs are most useful when deployed upward facing and on the seafloor in up to $11 \mathrm{~m}$ water depth. At deeper depths, waves with periods shorter than 4 seconds would not be observed. This type of device may also be deployed downward looking from a vessel, buoy, or side looking on a wall or post (O'Reilly et al. 1996). ADVs are ideally installed so that the sensor is within the near bottom boundary layer. Collocating an altimeter with the ADV allows determination of the location of the sensor with respect to changing bed elevations. The acoustic backscatter intensity from ADVs and ADCPs can be used to measure the concentration of suspended particles if properly calibrated to known sediment concentrations.

New Video and Radar Imaging Technologies. Remotely sensed radar and video imagery are new observation techniques that utilize the surficial expression of breaking and shoaling waves to infer information about the morphology of the surf zone. Both systems require waves of sufficient size to interact with the seafloor so are not well suited for low-energy, protected shorelines. While not direct measurements of topography or bathymetry, they can provide high spatial and temporal resolution observations that may provide insight into the evolution of nearshore placements. Since this category of instruments represents promising new methods in nearshore research, the remainder of this section will discuss their known capabilities, limitations, and potential applications.

Coastal video monitoring. The Argus image analysis and photogrammetry system is a remote sensing system that is capable of measuring wave parameters, morphology, and longshore currents at up to half-hourly time-steps during daylight hours (Holman and Stanley 2007). An Argus system can be composed of a single camera or multiple cameras depending upon the length of coastline that needs to be observed. They are typically mounted on temporary towers, permanent towers, or high-rise buildings and houses along the coastline. Typically, Argus cameras are deployed for long periods of time (months to years). To date, only one nearshore placement has been monitored using this method (Ott et al. 2011). In particular, this method may be able to show the progress of movement, spreading, and/or attachment of a placement feature to the shore. Additional information about Argus can be found on the Coastal Imaging Research Network's Website: https://coastal-imaging-research-network.github.io.

Radar Inlet Observing System (RIOS). RIOS is a radar imaging device capable of measuring wave parameters, inferring bathymetry and mean surface currents in nearshore areas (McNinch et al. 2012). RIOS has a range of approximately $3000 \mathrm{~m}$ from the transmitter/receiver, which is housed in a small trailer. The horizontal resolution at range is approximately $3 \mathrm{~m}$ and is capable of hourly observations. The range of the system may be decreased to achieve a higher resolution depending 
on the needs of monitoring (e.g., the placement dimensions are relatively small necessitating higher resolution). To obtain the best results, the system should be deployed for at least 3 to 6 months to capture different wave conditions at different tidal levels. RIOS-inferred bathymetry captures the general trends in the morphological evolution. Additionally, RIOS can capture the general surface current trends. An advantage of RIOS is its fairly large range and its ability to make bathymetric measurements during high energy events and at night. RIOS may be useful in the monitoring of nearshore placements by quantifying large-scale morphology changes, nearshore wave characteristics, and nearshore surface current changes due to the placement and subsequent evolution of a nearshore placement.

MONITORING PLANNING: In nearshore placement monitoring, once the pertinent measurement parameters and instrumentation are decided on, the schedule of field operations should be addressed. Physical monitoring of nearshore placement projects are often limited to finite budget resources; therefore, resources should be allocated in consideration of monitoring goals. Goals can be broadly defined in three categories: confirmation of benefits, documentation of issues, and quantification of the physical processes that are occurring. For example, the evidence for beach profile enhancement may be assembled from beach and nearshore transects measured over a sufficient period of time (1 year). Documentation of issues such as any fine-grained sedimentation of adjacent beaches may be elucidated from surficial sediment samples collected from the beach and/or intertidal zone. Quantification of the physical process that are occurring whether they result in benefits or issues may be determined by hydrodynamic measurements. Therefore, beach and nearshore surveying, sediment sampling, and hydrodynamic measurements would be the most useful to an engineer or planner monitoring a nearshore placement site. Table 2 is an optimal and schematic schedule for a nearshore placement monitoring project spanning 1-3 years using the instruments and methods discussed in this document. The monitoring schedule is idealized and considers an unlimited budget but should be customized depending on project goals, site specifics, and funding available for monitoring. Table 2 was compiled from and expanded on previous recommendations found in Anders (1989) and Beck et al. (2012) as well as author experience. Most of the nearshore placement monitoring should be conducted within the first year, when most of the changes to the placement will occur. After the first year, the remaining planning schedule should be re-evaluated in consideration of the results already found. For example, if the placement has nearly or completely dispersed after 1 year, there is no longer any benefit to monitoring. Figure 1 is an optimal and schematic view of the locations of transects, gauges, and sample locations; it too should be customized depending on placement and monitoring projects goals as well as site and placement specifics. 
Table 2. Optimal monitoring schedule for instruments and methods discussed in this document.

\begin{tabular}{|l|l|l|l|l|l|l|l|l|l|l|l|l|l|l|l|l|l|}
\hline $\begin{array}{l}\text { Monitoring } \\
\text { Component }\end{array}$ & $\begin{array}{l}\text { Initial } \\
\text { Placement }\end{array}$ \\
& Pre & Post & 1 & 2 & 3 & 4 & 5 & 6 & 7 & 8 & 9 & 10 & 11 & 12 & $\begin{array}{c}\text { Month } \\
15-27\end{array}$ & $\begin{array}{c}\text { Month } \\
21-33\end{array}$ & $\begin{array}{c}\text { Year } \\
0-3\end{array}$ \\
\hline & \\
\hline
\end{tabular}

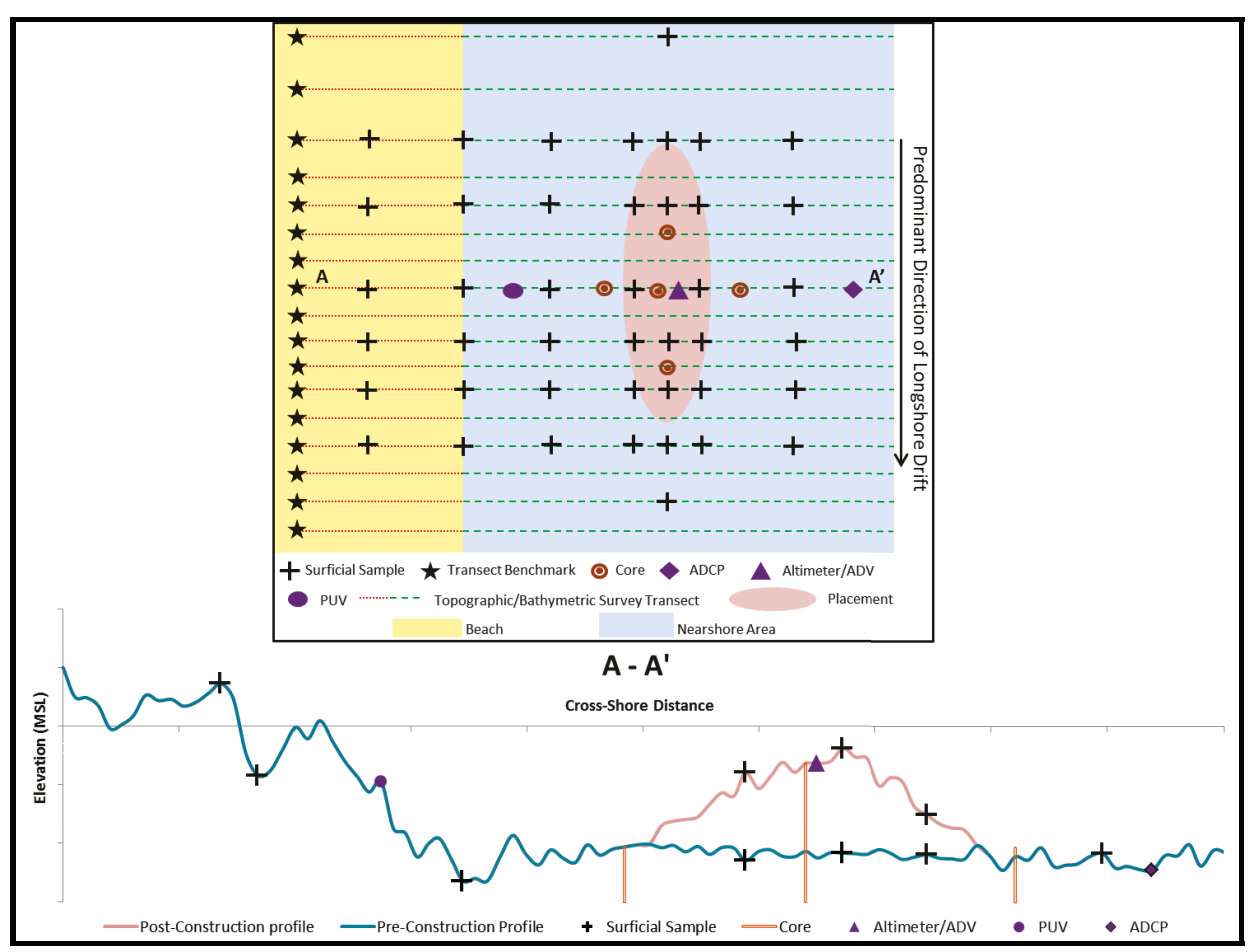

Figure 1. Plan (top) and cross-sectional (bottom) view of an idealized nearshore-placement monitoring project.

CASE STUDY: A nearshore placement was constructed and monitored offshore of Ogden Dunes, Indiana, by the USACE Chicago District in collaboration with the ERDC and the U.S. Geological Survey. Burns Waterway Harbor is located on the southern shore of Lake Michigan approximately $50 \mathrm{~km}$ east of Chicago, IL. The harbor was constructed in 1968 and includes a north/northeast-facing rubble mound breakwater and a west-facing rubble mound and armor stone bulkhead/jetty. Approximately $800 \mathrm{~m}$ west of Burns Waterway Harbor is the Burns Small 
Boat Harbor, which includes an east/west-facing rubble mound jetty, a north-facing rubble mound breakwater, and a northwest-facing jetty. The area around the harbor is predominately sandy beach with dunes and inland marshes. Offshore, the sedimentary material is mixed sand and clay, which is most likely derived from longshore transport from the northeast from bluff retreat and minimal river inputs ${ }^{1}$.

Numerous coastal management problems have developed in and around the vicinity of Burns Waterway Harbor. Sediment is accumulating east of Burns Waterway Harbor along a rubble mound containment jetty. Recently, maintenance dredging has occurred more frequently due to infilling of the ship channel. Significant erosion has been observed down drift of the harbor at Ogden Dunes and the National Park Service Indiana Dunes National Lakeshore. As a result, a RSM study was developed and executed to quantify the benefits and effects of the placement. In July 2016, 54,000 $\mathrm{m}^{3}$ of material dredged from the Burns Waterway Harbor navigation channel was placed in the nearshore off of Ogden Dunes, which is west and down drift of Burns Waterway Harbor. An additional $48,000 \mathrm{~m}^{3}$ of sediment was dredged from the Northern Indiana Public Service Company intake structure and placed in the same nearshore placement area in August and September 2016. The nearshore placement permit allows the dredged material to be placed at depths up to $5.5 \mathrm{~m}$, and dredging contractors prefer to place the material in the deepest possible location with small discrete placement mounds to prevent the sediment from obstructing the hanging gates of the scow from closing. The median grain size, $d_{50}$, for the dredged sediment is $0.15 \mathrm{~mm}^{2}$.

A nearshore placement monitoring study was developed to improve the understanding of wave conditions in the nearshore placement area, where the placed sediment is being transported, and how the beach responds to the nearshore placement. To monitor the geomorphic evolution of the nearshore placement and shoreline response, four topographic and bathymetric surveys were conducted. Due to budget and equipment availability, four single-beam bathymetric surveys and two multi-beam bathymetric surveys were conducted. Each bathymetric survey was conducted simultaneously with topographic beach surveys. The surveys were completed with the single beam following the grid shown in Figure 2, and the nearshore placement area is noted with the yellow rectangle. The post-construction survey immediately after the completion of the nearshore placement and another post construction survey 1 month after the completion of the nearshore placement will consist of multi-beam bathymetric surveys. Once the data were processed, nearshore morphologic changes and beach response were deduced from the topographic and multibeam bathymetric surveys to determine when the subsequent single beam bathymetric survey were to be conducted, which was approximately 2 months after the construction was completed. Highenergy wave events necessitated the timing of the final surveys.

\footnotetext{
${ }^{1}$ Morang, A., M., J. Chrzastowski, D. F. Bucaro, and J. A. Wethington. In preparation. Sediment Budget for the North Illinois Shore from the Wisconsin Border to Wilmette Harbor. ERDC/CHL Technical Report. Vicksburg, MS: U.S. Army Engineer Research and Development Center.

${ }^{2}$ Arnold, D. E., B. C. McFall, K. E. Brutsché, E. C. Maloney, and D. K. Bucaro. In preparation. Nearshore Placement Techniques in Lake Michigan. ERDC/CHL Technical Report. Vicksburg, MS: U.S. Army Engineer Research and Development Center.
} 


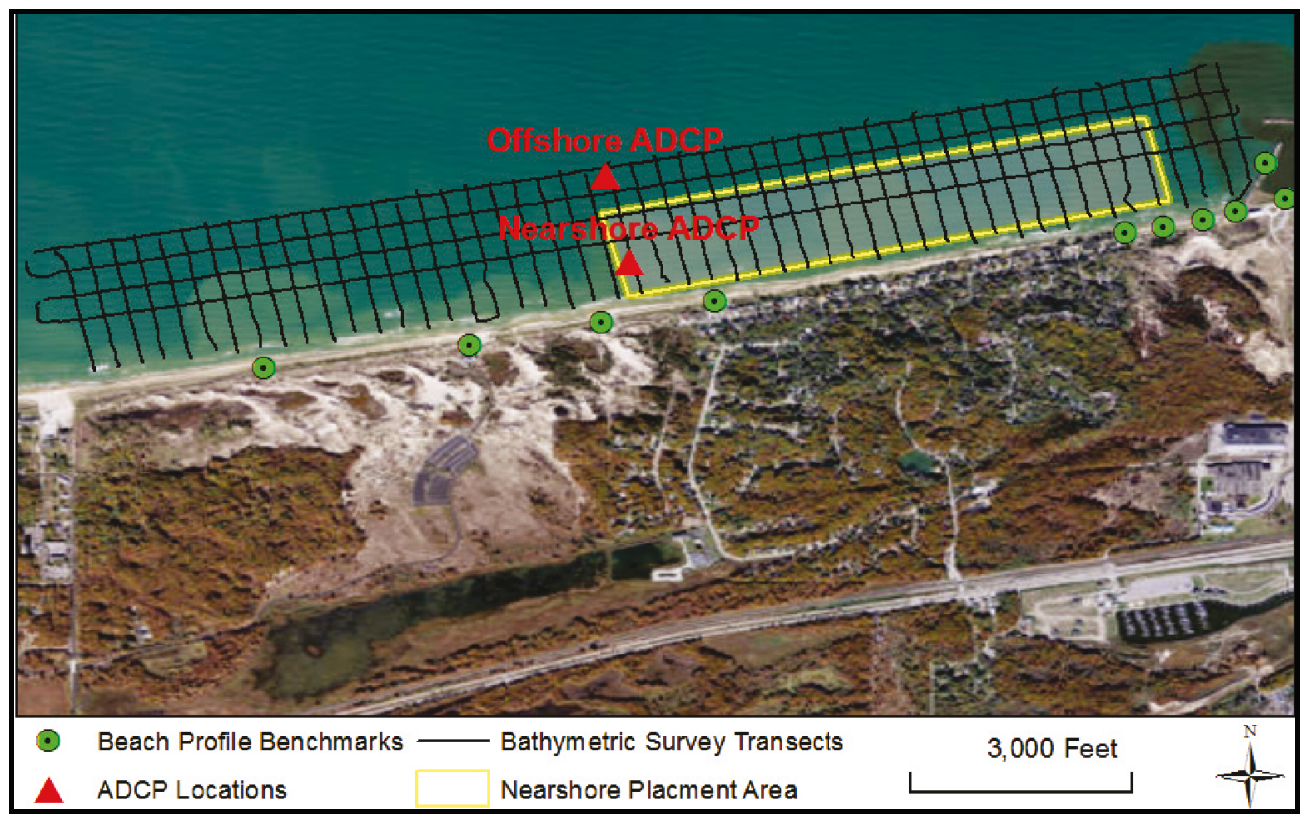

Figure 2. Nearshore placement site from Burn Harbor offshore of Ogden Dunes, IN, is noted with the yellow rectangle.

To directly measure the hydrodynamic forcing conditions responsible for the geomorphic evolution of the nearshore placement, two ADCPs were deployed prior to the construction of the nearshore placement. The intent of deploying an ADCP offshore of the nearshore placement and another shoreward of the nearshore placement was to determine the wave energy dissipation caused by the nearshore placement. Shoreline accretion in front of nearshore placements is common and generally attributed to calmer wave climate caused by wave energy dissipation from the nearshore placement. Results of the monitoring study will be published once the study is complete.

SUMMARY: This RSM-TN has summarized instrumentation and measurement techniques for monitoring nearshore placements. An ideal monitoring plan is shown using the majority of the discussed instrumentation, and a more typical monitoring study of a nearshore placement at Ogden Dunes, IN, is described. The goal of this technical note is to introduce a wide array of monitoring instrumentation and techniques presently available and provide an example monitoring case study in Lake Michigan.

ADDITIONAL INFORMATION: This Regional Sediment Management Technical Note (RSMTN) was prepared as part of the USACE National Regional Sediment Management (RSM) Program by Mr. Zachary Tyler, Dr. Brian C. McFall, and Dr. Katherine E. Brutsché, U.S. Army Engineer Research and Development Center (ERDC), Coastal and Hydraulics Laboratory (CHL), Vicksburg, MS; and Ms. Erin C. Maloney and Mr. David K. Bucaro of the U.S. Army Engineer District, Chicago (LRC). Questions pertaining to this RSM-TN may be directed to Mr. Tyler (Zachary.J.Tyler@usace.army.mil),Dr. McFall(Brian.C.McFall@usace.army.mil), or to the USACE National RSM Program Manager, Ms. Linda Lillycrop (Linda.S.Lillycrop@, usace.army.mil). Additional information regarding the USACE National RSM Program may be obtained from the RSM web site http://rsm.usace.army.mill.

This ERDC/TN RSM-18-6 should be cited as follows: 
Tyler, Z. J., B. C. McFall, B. C., K. E. Brutsché, E. C. Maloney, and D. K. Bucaro. 2018. Physical Monitoring Methods for the Nearshore Placement of Dredged Sediment. ERDC/TN RSM-18-6. Vicksburg, MS: U.S. Army Engineer Research and Development Center. http://dx.doi.org/10.21079/11681/26661

\section{REFERENCES}

Anders, F. J., and J. E Clausner. 1989. Physical Monitoring of Nearshore Sand Berms. EEDP-01-21. Vicksburg, MS: U.S. Army Engineer Waterways Experiment Station. https://erdc-library.erdc.dren.mil/xmlui/ bitstream/handle/11681/8842/EEDP-01-21.pdf? sequence $=1$ \&isAllowed $=y$.

Anderson, C. W. 2005. Turbidity: U.S. Geological Survey National Field Manual for the Collection of WaterQuality Data; Techniques of Water-Resources Investigations. Book 9, Chapter A6, Section 6.7. Version 2.1. https://water.usgs.gov/owq/FieldManual/.

Beck, T. M., J. D. Rosati, and J. Rosati. 2012. An Update on Nearshore Berms in the Corps of Engineers: Recent Projects and Future Needs. ERDC/CHL CHETN-XIV-19. Vicksburg, MS: U.S. Army Engineer Research and Development Center. https://erdc-library.erdc.dren.mil/xmlui/handle/11681/5004.

Brunier, G., J. Fleury, E. J. Anthony, A. Gardel, and P. Dussouillez. 2016. "Close-Range Airborne Structure-fromMotion Photogrammetry for High-Resolution Beach Morphometric Surveys: Examples from an Embayed Rotating Beach." Geomorphology 261: 76-88. https://doi.org/10.1016/j.geomorph.2016.02.025.

Brutsché, K. E., P. Wang, T. M. Beck, J. D. Rosati, and K. R. Legault. 2014. "Morphological Evolution of a Submerged Artificial Nearshore Berm along a Low-Wave Microtidal Coast, Fort Myers Beach, West-Central Florida, USA.” Coastal Engineering 91: 29-44. https://doi.org/10.1016/j.coastaleng.2014.04.010.

Brutsché, K. E., P. Wang, J. D Rosati, and T. M. Beck. 2015. "Evolution of a Swash Zone Berm Nourishment and Influence of Berm Elevation on the Performance of Beach-Nearshore Nourishments along Perdido Key, Florida, USA." Journal of Coastal Research 31(4): 964-977. https://doi.org/10.1016/j.coastaleng.2014.04.010.

Elgar, S., B. Raubenheimer, and R. T. Guza. 2001. "Current Meter Performance in the Surf Zone." Journal of Atmospheric and Oceanic Technology 18(10): 1735-1746. https://doi.org/10.1175/1520-0426(2001)018< 1735: CMPITS>2.0.CO;2.

Friedrich, H., B. W. Melville, S. E. Coleman, V. I. Nikora, and T. M. Clunie. 2005. "Three-Dimensional Measurement of Laboratory Submerged Bed Forms Using Moving Probes." In Proceedings, XXXI International Association of Hydraulic Engineering and Research Congress, 396-404.

Gallagher, E. L., W. Boyd, S. Elgar, R. T. Guza, and B. Woodward. 1996. "Performance of a Sonar Altimeter in the Nearshore." Marine Geology 133(3-4): 241-248. https://doi.org/10.1016/0025-3227(96)00018-7.

Hands, E. B., and M. Allison. 1991. "Mound Migration in Deeper Water and Methods of Categorizing Active and Stable Depths.” Coastal Sediments 91: 1985-1999.

Holman, R. A., and J. Stanley. 2007. "The History and Technical Capabilities of Argus." Coastal Engineering 54(6): 477-91. doi.org/10.1016/j.coastaleng.2007.01.003.

Jestin, H., P. Bassoullet, P. Le Hir, J. L'Yavanc, and Y. Degres. 1998. "Development of ALTUS, a High Frequency Acoustic Submersible Recording Altimeter to Accurately Monitor Bed Elevation and Quantify Deposition or Erosion of Sediments." In OCEANS'98 Conference Proceedings. Vol. 1. Institute of Electrical and Electronics Engineers. 10.1109/OCEANS.1998.725734.

Johnson, C., and P. A. Work. 2005. "Nearshore Dredged Spoil Mounds for Beach Erosion Prevention and Mitigation." Solutions to Coastal Disasters 2005 433-442. American Society of Civil Engineers. https://doi.org/10.1061/40774(176)44.

Kraus, N. C., M. Larson, and R. Wise. 1998. Depth of Closure in Beach-fill Design. CETN-II-40. Vicksburg, MS: U.S. Army Engineer Waterways Experiment Station, Coastal and Hydraulics Laboratory. 
Lohrmann A., R. Cabrera, and N. C. Kraus. 1994. “Acoustic Doppler Velocimeter (ADV) for Laboratory Use.” In Proceedings, Symposium on Fundamentals and Advancements in Hydraulic Measurements and Experimentation, 351-365. American Society of Civil Engineers.

Masselink, K., and A. Kroon. 2009. "Morphology and Morphodynamics of Sandy Beaches." In Coastal Zones and Estuaries, 221-243. Paris, France: Encyclopedia of Life Support Systems.

McNinch, J. E., K. L. Brodie, and R. K. Slocum. 2012. "Radar Inlet Observing System (RIOS): Continuous Remote Sensing of Waves, Currents, and Bathymetry at Tidal Inlets." In 2012 Oceans, 1-8. Institute of Electrical and Electronics Engineers. 10.1109/OCEANS.2012.6404957.

Moulton, M., S. Elgar, and B. Raubenheimer. 2014. "Improving the Time Resolution of Surfzone Bathymetry using In Situ Altimeters.” Ocean Dynamics 64(5): 755-770.

O'Reilly, W. C., T. H. C. Herbers, R. J. Seymour, and R. T. Guza. 1996. "A Comparison of Directional Buoy and Fixed Platform Measurements of Pacific swell." Journal of Atmospheric and Oceanic Technology 13(1): 231238. https://doi.org/10.1175/1520-0426(1996)013<0231:ACODBA>2.0.CO;2.

Ott, M., H. Moritz, and G. Kaminsky. 2011. "The Southwest Washington Littoral Drift Restoration Project: Evaluation of Intertidal Placement of Mouth of the Columbia River Dredged Material on Benson Beach; Preliminary Results." In American Shore and Beach Preservation Association National Coastal Conference Proceedings.

Poppe, L. J., A. H. Eliason, J. J. Fredericks, and R. R. Rendigs. 2000. Grain-Size Analysis of Marine Sediments: Methodology and Data Processing. U.S. Geological Survey Open-File Report 00-358.

Rusello, P. J., A. Lohrmann, E. Siegel, and T. Maddux. 2006. "Improvements in Acoustic Doppler Velocimetry." In Proceedings, Seventh International Conference on Hydroscience and Engineering, ICHE-2006. https://pubs.usgs.gov/of/2000/of00-358/text/chapter1.htm.

Spore, N. J., and K. L. Brodie. 2017. Collection, Processing, and Accuracy of Mobile Terrestrial Lidar Survey Data in the Coastal Environment. ERDC/CHL TR-17-5. Vicksburg, MS: U.S. Army Engineer Research and Development Center. doi.org/10.21079/11681/22189.

Tetra Tech EM, Inc. 2003. Literature Review and Report: Surface Sediment Sampler Database. Report prepared for U.S. Environmental Protection Agency, Washington DC.

Tuell, G., K. Barbor, and J. Wozencraft. 2010. "Overview of the Coastal Zone Mapping and Imaging Lidar (CZMIL): A New Multisensor Airborne Mapping System for the U.S Army Corps of Engineers." In Proceedings, SPIE 7695; Algorithms and Technologies for Multispectral, Hyperspectral, and Ultraspectral Imagery XVI.

United States Army Corps of Engineers (USACE). 2013. Hydrographic Surveying. EM 1110-2-1003. Washington, DC.

Wang, P., K. E. Brutsché, J. W. LaGrone, T. M. Beck, J. D. Rosati, and L. S. Lillycrop. 2013. Performance Monitoring of a Nearshore Berm at Ft. Myers Beach, Florida: Final Report. ERDC/CHL TR-13-11. Vicksburg, MS: U.S. Army Engineer Research and Development Center.

Westoby, M. J., J. Brasington, N. F. Glasser, M. J. Hambrey, and J. M. Reynolds. 2012. "Structure-from-Motion Photogrammetry: A Low-Cost, Effective Tool for Geoscience Applications." Geomorphology 179: 300-314. doi.org/10.1016/j.geomorph.2012.08.021.

NOTE: The contents of this technical note are not to be used for advertising, publication, or promotional purposes. Citation of trade names does not constitute an official endorsement or approval of the use of such products. 